\title{
The Use of Hot Air Welding Technologies for Manufacturing E-textile Trasmission Lines
}

\author{
Senem Kursun Bahadir, Fatma Kalaoğlu, and Simona Jevšnik* \\ Textile Technologies and Design Faculty, Istanbul Technical University, Istanbul 34437, Turkey
}

(Received July 29, 2014; Revised April 15, 2015; Accepted May 12, 2015)

\begin{abstract}
This study investigated the potential possibilities for obtaining textile transmission lines by incorporating conductive yarns into fabrics through a hot air welding process. Hot air sealing for obtaining textile transmission line was conducted using $100 \%$ PES woven fabric, GoreTex ${ }^{\circledR}$ waterproof welding tape and seven different conductive yarn types, in order to form different textile transmission lines. By manufacturing using a hot air seam-sealing machine different welding parameters like welding temperature, pressure and velocity were chosen in order to find an optimal welding process for the selected fabric samples. The effects of welding parameters were examined on the electrical properties of the textile transmission lines in terms of conductivity and signal-transferring capability. Besides, the bending properties and morphologies of the welded textile transmission lines were also characterized and subjective evaluations of the appearances of textile transmission lines like puckering and the visual appearances of the surface sides of the welded textile transmission lines. The results based on conductivity and signal transferring capabilities were really promising for the manufacturing of etextile transmission lines via hot air welding technology. Moreover, the results based on bending properties showed that the lower the welding parameters the less rigid the hot air welded textile transmission lines became after welding all the used conductive yarns. Further, suitable combinations of welding parameters with the used components of textile transmission assured suitable visual appearances of the welded textile transmission lines. In this respect this research work offers a usage for hot air welding technology regarding the formations of textile transmission lines which are reliable and durable in functionality while still preserving the textiles' aspects.
\end{abstract}

Keywords: Textile transmission lines, Welding, E-textiles, Conductive yarns, Hot air seam sealing

\section{Introduction}

Methods for joining textile materials have been successfully implemented since the 1940s within the sector of technical textiles and later on thread-less joining spread towards areas like sailing, inflatable boats, truck-awnings, bag filters, inflatable toys, and nowadays is also present in garment areas like underwear and sportswear. In fact, the welding and bonding of textiles represent a great opportunity for providing good performance and aesthetic appearance compared to traditional sewing method while also increasing the automation of the sewing process. During the traditional sewing technique, which is a highly labor-intensive process, individual fabric panels are joined together with sewing threads of adequate strengths, elasticity and aesthetic properties. However, with this technique discontinuous joints and perforated seams can be seen, and this result is them being interpreted as disadvantages regarding some textile products. On the other hand, welding and bonding technologies ensure continuous and non-perforated seams by providing faster production, lower waste material and low energy consumption [1-3].

Within the welding mechanism two thermoplastic materials are brought together and stuck to each other. This process is mainly based on the molecular interlocking of two surfaces which are in contact with each other at their melt temperatures. When the surfaces are subjected to heat, the

*Corresponding author: simonajevsnik@gmail.com stabilities of the polymer molecules within the materials are disturbed and hence, disentanglement of the polymer molecules occurs. This phenomenon, leading the molecules to freeing their chain-ends, a condition is created for strong adhesion between two materials which are in close contact with each other when they are around their melt temperatures [4].

In order to create a welded area, therefore, a heat-transfer mechanism should be applied between two thermoplastic surfaces positioned within close contact. Different techniques can be used for satisfying these conditions. These methods can be grouped into three categories: thermal (by conduction or convection); radiation (e.g. infrared, laser or induction) and friction (e.g. rotary, vibrational, or ultrasonic). The more used welding and bonding technologies for textiles are hot air fabric and hot wedge fabric welding, ultrasonic, laser, and radio frequency welding [4-8]. Within textile arena two particular techniques are used for obtaining welded seams. In the first technique, a thermoplastic film is used to bond two fabrics together while in the second one two thermoplastic fabrics are brought together and stuck to each other with the principle based on the molecular interlocking mentioned above [7,9].

The literature reviews concerning weld-line formation on textiles mainly focus on the qualities of the welded seams. For instance; in their study Kakubčioniene et al. examined the qualities of hot welded seams using the thermoplastic type and reported that the qualities of fabric bonding depend on proper selections of parameters during the two bonding 
stages: film transfer and layer bonding [10]. In addition, they stated that bonding strength depends on structure type, bearing surface and treatment and a bonding problem can appear when using teflon and silicon finishes. The literature also mentions that since some dyestuffs react differently to heat, the bonding strengths of the welded fabrics may be affected by some dyestuffs and especially by darker colors [8]. There are also some studies focusing on ultrasonic welded seams. One of the studies indicated that due to the thicknesses of the layers, some of the ultrasonic welded seams are of insufficient qualities in terms of bonding strengths [11]. In a study concerning the ultrasonic sealing of polyester and spectra fabrics, the effects of two important welding parameters like weld pressure and weld time were investigated on a fabric's bond strength [12]. In another study, the heating and bonding mechanisms of ultrasonic welding processes were studied for fabrics when building smart seams by incorporating optic fibers [13]. Application of the laser transmission welding method has also been tried on textiles. It was indicated that the laser welding technique is a suitable method for joining textile layers made of polyamide 6.6 with sufficient seam strength and was therefore suggested as an alternative way of producing airbag fabrics [14]. Further, the effects of vibration welding parameters have also been studied regarding the qualities of those joins made of polyamide 6.6 [15]. In the literature a handful of attempts can be observed regarding the issue of using welding technologies within the textile area and their effective parameters on textile joining. Although welding technology presents a substantive challenge for the textile industry, less attention has been paid to this topic by textile researchers.

In an e-textile system, satisfying reliable electrical transmission among electronic components without any interruption is a crucial issue since such interconnections are pathways for supplying power or transmitting digital/analog signals to electronic components $[16,17]$. E-textile transmission lines for different applications have been obtained through several methods such as direct insertion of conductive yarns, while weaving or knitting processes; depositions of electroconductive thin layers on flat textile surfaces; overprinting or coating of conductive materials/polymers like polypyrrole, polyaniline, polythiophene, etc., as well as metal particles, carbon nanotubes and carbon black particles on flat textile surfaces, and direct insertions of conductive yarns through sewing or embroidery methods [18-21]. During the construction stages of textile transmission lines they are subjected to numerous mechanical stresses, which can lead to failure of the line in terms of resistivity and signal transmission. The value of this failure can either decrease the quality of the signal transmission or further result in failure of the whole etextile system.

In this respect, this research work offers the usage of hot air welding technology for the formation of textile transmission lines which are reliable and durable in functionality while preserving the textiles' aspects. In this study, e-textile transmission line formation was accomplished by the use of hot air welding technology and the quality of welded textile transmission lines discussed regarding the various aspects of conductive yarns. In order to carry out the research, two layered fabrics containing conductive yarns were considered for creating textile transmission lines. Different conductive yarn types with different linear resistance values were used for forming the transmission lines and were hidden within the textile's structure without any undulation. In order to manufacture via a hot air welding machine, different welding parameters were chosen in order to discover the optimal welding process for the fabric samples. The electrical properties of hot air welded transmission lines with respect to conductivity and signal transference capability were measured and evaluated. Additionally, the morphologies of the welded textile transmission lines were also characterized by scanning electronic microscopy and subjective evaluation of textile transmission appearance, like puckering and the visual appearance of the face-side of the welded transmission lines was also carried out. Besides, the fabric's bending properties are also discussed throughout the paper in order to obtain the information about the bending behaviors of those welded seams using conductive yarns. The remainder of the paper is organized as follows. Section 2 describes the experimental study for designing and manufacturing textile transmission lines by the hot air welding technique and the test methods for measuring the physical and electrical properties of the welded samples. Section 3 presents the results based on electrical and physical tests, with a discussion. The main findings and contributions are drawn, and future developments are suggested in the conclusion.

\section{Experimental}

The development of textile transmission lines for e-textile applications includes a design process based hot air welding technologies as well as testing procedures of electrical, mechanical and surface properties. During the presented research welded textile transmission lines manufactured via the hot air seam sealing method were tested from several aspects, as shown in Figure 1.

\section{Design and Manufacturing of Textile Transmission Lines}

An e-textile structure consisting of transmission lines was designed in two-layered fabric constructions, as seen in Figure 2. The length of the structure was arranged at $30 \mathrm{~cm}$ while the width was arranged at $5 \mathrm{~cm}$. When considering the manufacturing issues, and compatibility with the hot air welding machine, $100 \%$ polyester fabric with a plain weave was chosen as a thermoplastic material for the base (first) layer of the structure. The fabric density in the warp direction was $21.4 \mathrm{picks} / \mathrm{cm}$ and in the weft direction $18.4 \mathrm{ends} / \mathrm{cm}$, 


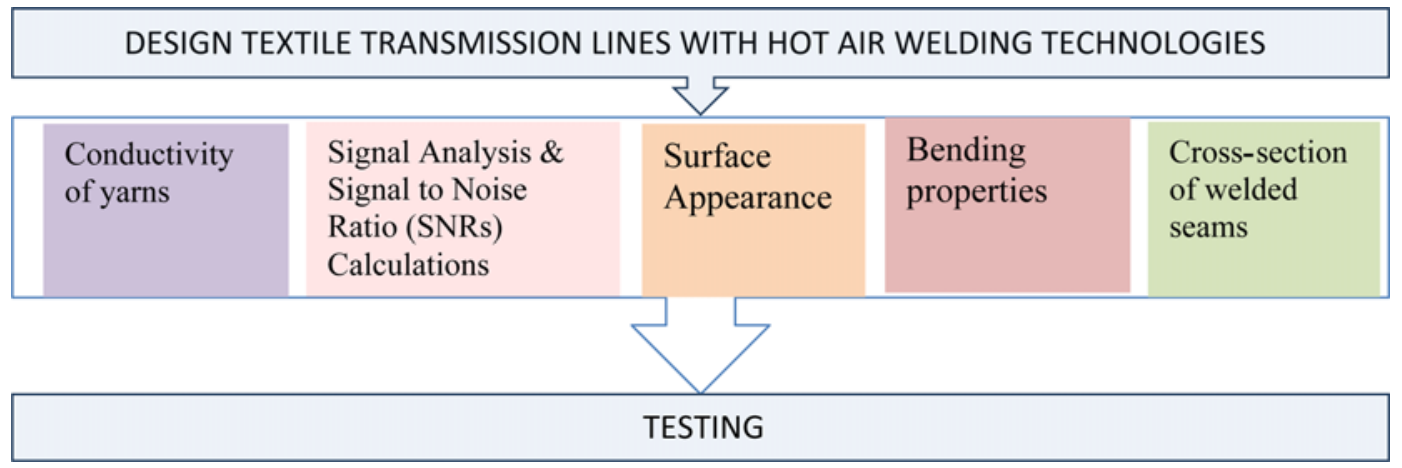

Figure 1. Aspects for analysing textile transmission lines.

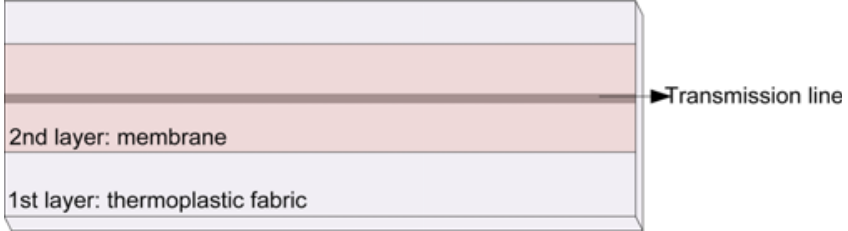

Figure 2. Schematic diagram for e-textile structure having transmission line.

the thickness of the fabric was $0.202 \mathrm{~mm}$ and the fabric weight was $163.5 \mathrm{~g} / \mathrm{m}^{2}$. The fineness of the warp and weft yarns was the same in both directions at a value of 65.7 tex. For the second layer, a Goretex ${ }^{\circledR}$ membrane with a width of $1 \mathrm{~cm}$ was chosen in order to prevent probable short circuits during signal transmission, as well as to obtain a water resistant fabric structure by considering the usage issues of e-textiles. A Goretex ${ }^{\circledR}$ membrane is made of two layers (layer 1 - waterproof film and layer 2 - hot melt adhesive film), thickness is $0.163 \mathrm{~mm}$, width $23 \mathrm{~mm}$ weight $199.78 \mathrm{gm}^{-2}$.

Seven commercial conductive yarns divided in two groups, stainless steel and silver-coated PA were used to create transmission lines within the two layered fabric structure. The conductive yarns were also distinguishable among the electrical linear resistance. All the used conductive yarns were produced by the twisting technologies of filament fibers.
The conductive yarns were positioned along a straight trajectory in the middle of the fabric without any undulation. Hence, the transmission line seen in Figure 2 was hidden by the replacement of the conductive yarn between the fabric and membrane during the manufacturing process. The properties of the conductive yarns used for manufacturing the e-textile fabric with welding technologies are presented in Table 1.

To set up the manufacturing process in order to find the optimal working process parameters for the fabric samples, pre-work on the samples was firstly carried out to see which application procedure and then the different welding parameters within a determined working interval would be chosen. The pressure was set at 6.5 bar constantly during all samples' manufacturing processes while temperature and velocity were arranged at two different levels, as shown in Table 2. Hence, three sets of welding processes for the manufacturing of e-textile transmission lines were used for the experimental

Table 2. Welding parameters for manufacturing e-textile transmission lines

\begin{tabular}{cccc}
\hline & $\begin{array}{c}\text { Temperature } \\
\left(\mathrm{T} /{ }^{\circ} \mathrm{C}\right)\end{array}$ & $\begin{array}{c}\text { Velocity } \\
\left(\mathrm{v} / \mathrm{mmin}^{-1}\right)\end{array}$ & $\begin{array}{c}\text { Pressure } \\
(\mathrm{p} / \mathrm{bar})\end{array}$ \\
\hline Weld Set 1 & 350 & 2.5 & 6.5 \\
Weld Set 2 & 450 & 2.5 & 6.5 \\
Weld Set 3 & 350 & 1.5 & 6.5 \\
\hline
\end{tabular}

Table 1. The properties of the conductive yarns used as transmission lines

\begin{tabular}{|c|c|c|c|c|c|c|}
\hline $\begin{array}{c}\text { Conductive yarn } \\
\text { no } \\
\end{array}$ & Material type & $\begin{array}{c}\text { Weight } \\
(\mathrm{g} / \mathrm{m})\end{array}$ & $\begin{array}{l}\text { Yarn diameter } \\
(\mu \mathrm{m})\end{array}$ & $\begin{array}{c}\text { Yarn count } \\
(\mathrm{dtex})\end{array}$ & $\begin{array}{c}\text { Yarn twist } \\
\left(\mathrm{m}^{-1}\right)\end{array}$ & $\begin{array}{c}\text { Linear resistance } \\
(\Omega / \mathrm{m})\end{array}$ \\
\hline 1 & $100 \%$ stainless steel & 0.82 & 632 & $275 \times 3$ & 224 & $<12$ \\
\hline 2 & $100 \%$ stainless steel & 0.28 & 395 & $100 \times 1$ & 134 & $<25$ \\
\hline 3 & $100 \%$ stainless steel & 0.19 & 464 & $90 \times 2$ & 207 & $<35$ \\
\hline 4 & $100 \%$ stainless steel & 0.13 & 315 & $90 \times 1$ & 149 & $<70$ \\
\hline 5 & $99 \%$ Silver coated PA & 0.125 & 764 & $235 / 34 \times 4$ & 349 & $<50$ \\
\hline 6 & $99 \%$ Silver coated PA & 0.0113 & 377 & $70 / 34 \times 1$ & 130 & $<420$ \\
\hline 7 & $99 \%$ Silver coated PA & 0.00450 & 142 & $30 \times 1$ & 125 & $<2000$ \\
\hline
\end{tabular}




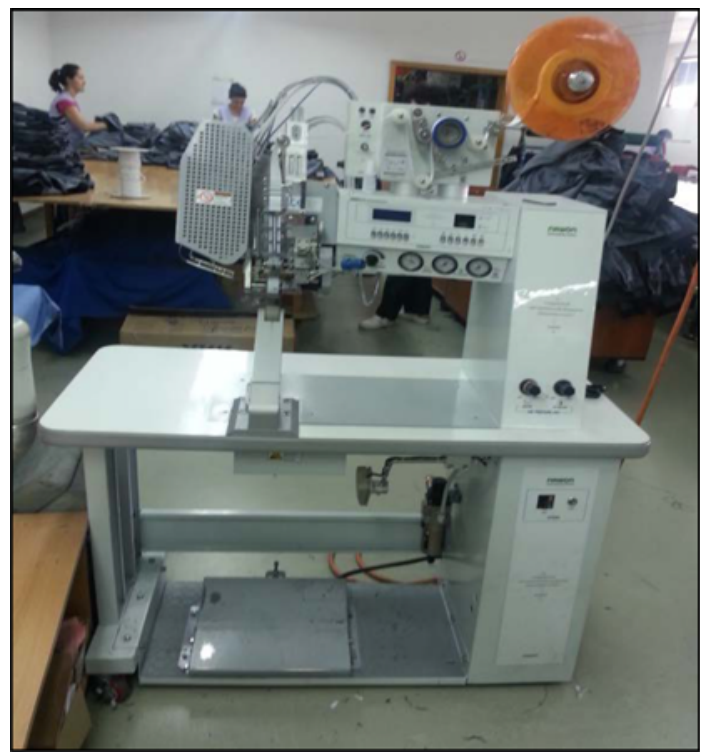

Figure 3. Hot air seam sealing machine NAWON.

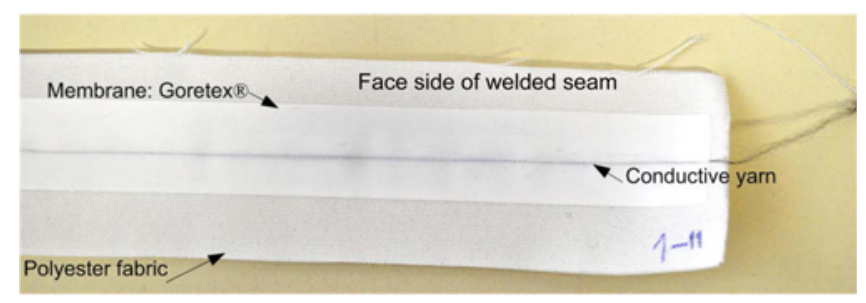

Figure 4. Textile transmission line sample manufactured via hot air seam sealing machine.

set-up. The intent of our study was to determine whether there is any significant difference between signal transferring capabilities and the conductivities of textile transmission lines when they are subjected to different welding parameters.

A hot air seam-sealing machine from NAWON Machinery Co., as shown in Figure 3, was used to manufacture samples having textile transmission lines.

The basic characteristics of the used hot air seam-sealing machine from NAWON are:

- Type: HTM-3877 LDI

- Compressed Air: $2.2 \mathrm{~kW}$

- Width of adhesive tape: 12-23 mm (Optional extra)

- Upper roller lift: $30 \mathrm{~mm} /$ Optional extra

- Speed: 1-18 M/min. Digital read-out of operating speed

- Max temperature: Up to $699^{\circ} \mathrm{C}$

- Heater Capacity: 3600 W

For instance, a textile transmission line sample manufactured via the hot air seam-sealing machine is shown in Figure 4. As seen in Figure 4, the conductive yarn used as the transmission line for satisfying signal transmission was hidden within the two-layered structure without any undulation. During the manufacturing, it was successfully positioned between the polyester fabric and the membrane along a direct trajectory.

\section{Testing the Electrical Properties of the Textile Transmis- sion Lines}

Since the conductivity and signal transmission qualities are the mainly relevant parameters for the functionalities of e-textiles, the electrical properties of the textile transmission lines were tested in terms of conductivity and signal transferance capabilities.

Yarn conductivity was measured on both the non-welded yarns and those yarns after the welding processes. A Keithley ${ }^{\circledR}$ multi-meter was used for measuring the conductivities of yarns. The linear resistances of the yarns were calculated in ohms per meter $(\Omega / \mathrm{m})$ by taking measurements along the yarn samples' lengths. The measuring process was repeated three times for each welded sample. The resistances of the yarns were measured according to the 4-point probe method.

Signal Analysis and signal-to-noise ratio (SNRs) calculations were tested on non-welded and welded conductivity yarns as triple repetitive methods on the samples.

Measurements were performed using a Tektronix ${ }^{\circledR}$ TDS 2012B oscilloscope and a Tektronix ${ }^{\circledR}$ AFG3022B Function Generator. During the measurements the function generator was firstly connected to the e-fabric samples for satisfying electrical signal generation over the transmission lines. Then, the oscilloscope was connected to the transmission lines of the samples in order to observe the electrical signals' waveforms. Afterwards, the obtained signals over the transmission lines were directly transferred and recorded on the computer for signal analysis. The schematic diagram for the signal measurements is given in Figure 5.

The signals extracted from the oscilloscope were in their basic forms, meaning they were unprocessed and included substantial electrical noise. In order to make any reasonable comparisons between the signal-transferring capabilities of the e-fabric samples which were subjected to different sets of welding processes, the recorded signals were analyzed using Matlab ${ }^{\circledR}$ R2010b software, and their SNRs values calculated.

The SNR (signal-to-noise ratio) is the ratio of the signal of interest (signal power) to undesirable signal (noise power) [23]. The SNR can be estimated by calculating the ratio of signal power to noise power. In our study, once the signal was recorded, noise level (unwanted signal) and noise amplitude were determined by signal processing in MATLAB ${ }^{\circledR}$.

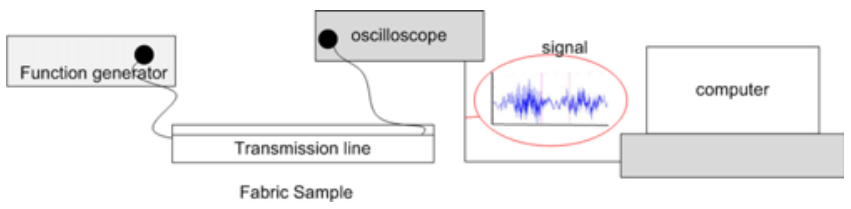

Figure 5. Schematic diagram for signal measurements over transmission lines. 
Since the signal and noise were measured within the same impedance, the SNR was obtained by calculating the square of the amplitude ratio, where $\mathrm{A}$ is the root mean square (RMS) amplitude:

$$
S N R=\left(\frac{A_{\text {signal }}}{A_{\text {noise }}}\right)^{2}
$$

Generally, SNRs are expressed on a logarithmic decibel scale. In electronics, the decibel is a convenient way for engineers to describe the input to output ratios of either power or voltages. Therefore, in order to quantify the signal qualities of each sample, the $S N R_{d B}$ values of each sample were calculated by using following equations [22].

$$
\begin{aligned}
& S N R_{d B}=10 \log _{10}\left(\frac{P_{\text {signal }}}{P_{\text {noise }}}\right)=P_{\text {signal }, d B}-P_{\text {noise }, d B} \\
& S N R_{d B}=10 \log _{10}\left(\frac{A_{\text {signal }}}{A_{\text {noise }}}\right)^{2}=20 \log _{10}\left(\frac{A_{\text {signal }}}{A_{\text {noise }}}\right)
\end{aligned}
$$

A higher SNR value is indicative of better signal quality and less noise, which is preferred. For each calculation 2500 data was collected for one signal transfer. From this basic data the mean SNRs of each sample belonging to each conductive yarn type were calculated for each stage of the welding process. The results from signal analyses were used to evaluate the signal transference capabilities of the samples according to conductive yarn type and welding parameters.

All tests were carried out under laboratory conditions $\left(20^{\circ} \mathrm{C}\right.$ and $\left.65 \% \mathrm{RH}\right)$.

\section{Visual Appearance and Microstructure Analysis}

Apart from the electrical properties, the visual appearance like the puckering of textile transmission lines and the surface appearances on the face sides of the textile transmission lines were observed, as well as the microscopic images of conductive yarns inside the fabric structure.

The appearances were assessed subjectively in terms of the surface appearances on the face sides and the puckering of the welded textile transmission lines. Evaluation of the surface appearance was based on the frequencies of occurrences regarding the visual conductive yarn on the surfaces of the face-side of the welded transmission lines. The frequencies were categorized into three groups: non-visible, slightly visible (from 0 to 3 visible points on the seam distance $5 \mathrm{~cm}$ ) and highly visible points (more than 3 visible on the seam length $5 \mathrm{~cm}$ ). The puckering was evaluated individually according to AATCC standard $88 \mathrm{~B}$ since visually the puckering phenomena around welded conductive yarns by welding tape locks similarly to seam puckering by conventional sewing. According to the AATCC method, seam appearance is classified into five grades: grade 1 refers to the worst fabric which is heavily puckered and grade 5 refers to a smooth fabric with little pucker or no pucker at all, as shown in Figure 6.

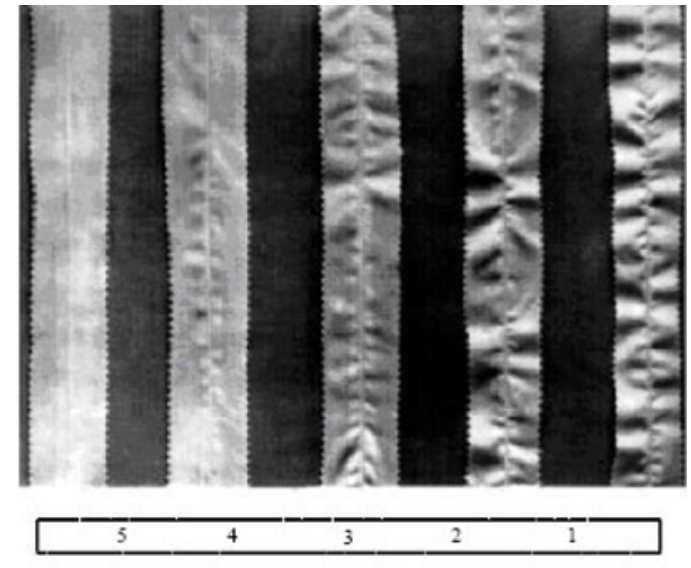

Figure 6. Panels for the seam inspection.

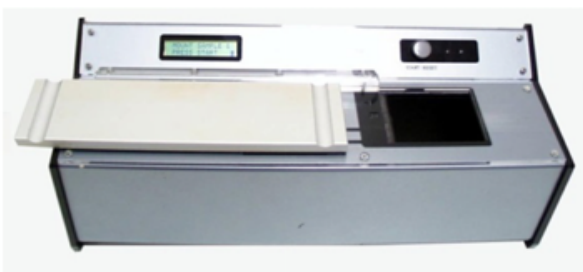

(a)

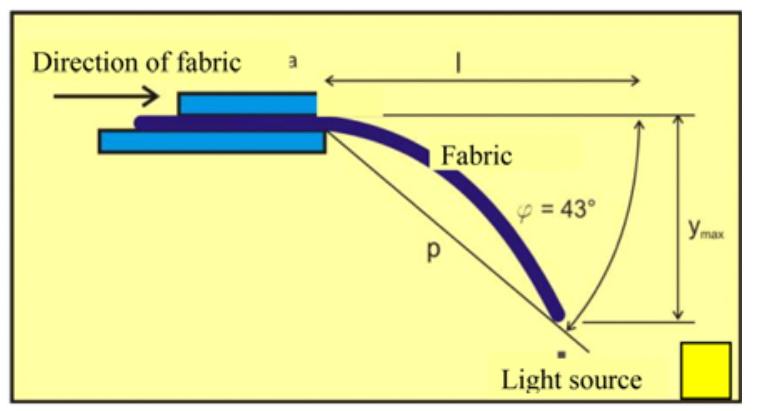

(b)

Figure 7. FAST bending tester; (a) with schematic representation of bending measurement (b).

In addition to the visual appearances of the welded seams, longitudinal microscopic images of the conductive yarns and cross-sections of the welded seams were also observed using a JMS-6060LV scanning electroscopy microscope.

\section{Bending}

Since the rigidity of the fabric structure is an important issue for e-textiles from the point of interactive clothing or wearable electronics, the bending properties of the textile transmission lines were also studied during this research. The stiffness property is crucial in order to measure the performance during the production process as well as during the usages of welded textile products.

The bending properties were determined using a bending 
meter of the SiroFAST-2 measuring system, as shown in Figure 7. The bending tester as shown in Figure 7 measures a seam's bending length according to BS 3356-1961.

The bending lengths of the fabric were measured on samples $(5 \mathrm{~cm} \times 20 \mathrm{~cm})$ prepared in the warp direction. The welded seams were placed in the middles of the samples' widths. The bending rigidities from the face and back-sides were observed, and bending rigidity $\mathrm{B}$ was calculated after three repetitions as [24]:

$$
B=C^{3} \times 9.81 \times 10^{-6}
$$

where, $B$ : bending rigidity, $\mu \mathrm{Nm}^{-1}$

$W$ : fabric weight, $\mathrm{g} / \mathrm{m}^{2}$

$C$ : bending length, $\mathrm{mm}$

The bending measurements were done under standard testing conditions, i.e. temperature of $20 \pm 2{ }^{\circ} \mathrm{C}$ and $65 \pm 2 \%$ relative air humidity.

\section{Results and Discussion}

\section{Conductivity of Textile Transmission Lines}

The linear resistances of the welded conductive yarns according to the defined welding sets (Table 2), are presented in Table 3.

As the temperature increased the conductivities of the welded conductive yarns, those having conductivity values of less than $70 \mathrm{ohm} / \mathrm{m}$, remained almost at the same values. However, the linear resistance of the yarn No. 6 (silver coated polyamide) dramatically increased from $420 \mathrm{ohm} / \mathrm{m}$ (see Table 1) to $524 \mathrm{ohm} / \mathrm{m}$ when the temperature increased. In addition, with yarn No.7 (silver coated polyamide) at $450{ }^{\circ} \mathrm{C}$ weld temperature, the transmission line could not be formed. Therefore, no result was obtained since no seam was observed. This result may be attributed to excessive melting of the coated polyamide fibers at the interface which led to failure of the transmission line. When heat was applied to the thermoplastic PES the fabric temperature increased, thus causing the polymer to melt or partially melt at that location. Consequently, intermolecular diffusion occurred between the PES fabric and the membrane, thus

Table 3. Linear resistances of welded conductive yarns $(\Omega / \mathrm{m})$

\begin{tabular}{cccc}
\hline Yarn no. & Weld Set 1 & Weld Set 2 & Weld Set 3 \\
\hline 1 & 12.33 & 12.00 & 12.33 \\
2 & 25.00 & 25.00 & 25.67 \\
3 & 30.67 & 33.33 & 34.00 \\
4 & 69.00 & 69.67 & 70.67 \\
5 & 50.33 & 52.00 & 52.40 \\
6 & 507.33 & 524.33 & 592.00 \\
7 & 3003.33 & $*$ & 3046.67 \\
\hline
\end{tabular}

*Indicate no seam was formed; therefore, no result was obtained. having an effect on new bond formation. Since the conductive yarn was positioned between the PES fabric and the membrane, a new bond formation with the given heat effect on the conductive yarn surface and these new bonds probably adhered to the coated conductive yarn's surface, thus leading to failure of the line in terms of conductivity. Moreover, with yarn No. 13 at temperature $\mathrm{T}=350{ }^{\circ} \mathrm{C}$, the obtained linear resistance was around $3000 \mathrm{ohm} / \mathrm{m}$, which indicated a dramatic increase (from $2000 \mathrm{ohm} / \mathrm{m}$ to 3000 $\mathrm{ohm} / \mathrm{m}$ ) when compared to its original linear resistance value as shown in both Table 1 and Table 3. Indeed, these trends could be explained by the conductivities of the materials. More specifically, when the weight of the coated conductive yarn was low, that means the amount of coating with conductive material was less, due to lower amount of conductive material over the surface of the yarn, coated conductive yarn exhibits higher resistivity which means a decrease in conductivity level of the conductive yarn $[25,26]$. In our case, yarns No.6 and No.7 were the silver-coated polyamide yarns with lesser weights when compared to other conductive yarns and their conductivity levels were also lower than others with higher linear resistance values (see Table 1). For that reason, when they were subjected to heat at temperatures greater than $350{ }^{\circ} \mathrm{C}$ during the hot air welding process, their conductivity levels inversely affected and decreased as obtained higher linear resistance values. Based on these results, therefore, it can be concluded that during the welding process with any increase in temperature, the conductivity of a transmission line made of coated conductive yarn may be decreased due to its amount of surface coating or in other words due to its conductivity level.

In continuation, velocity was taken as weld (sealing) time because the exposure length to the hot air was constant at any given time. As the velocity decreased or the exposure time increased, the linear resistances of the stainless steel conductive yarns remained almost the same whereas the linear resistances of both silver coated yarns No.6 and No.7 again dramatically increased from $420 \mathrm{ohm} / \mathrm{m}$ to $592 \mathrm{ohm} / \mathrm{m}$ and $2000 \mathrm{ohm} / \mathrm{m}$ to $3046 \mathrm{ohm} / \mathrm{m}$, respectively, as seen in both Table 1 and Table 3 . This phenomenon could be similarly explained due to their conductivity levels. As the exposure time increased, the amount of energy transmission to the fabric increased, thus allowing the fibers between the two fabrics layers to bond with each other. Since there was a conductive yarn between these layers, the fibers also bonded onto the conductive yarn's surface resulting in coating of the surface of the conductive yarn so that a failure occurred at the conductivity level.

However, from the point of view of e-textiles, those conductive yarns with linear resistances of less than $200 \mathrm{ohm} / \mathrm{m}$ were preferable for signal transmission. Those conductive yarns with linear resistances greater than $600-700 \mathrm{ohm} / \mathrm{m}$ are generally used for RF Shielding, Electrostatic discharge (ESD) and anti-microbial applications instead of signal 
transmission line [25]. Therefore, the obtained results based on conductivity were promising for the manufacturing of etextile transmission lines via hot air welding technology.

\section{Signal Transference Capabilities of Welded E-textile Transmission Lines}

The results of signal analysis are presented in Table 4 .

It was observed that the signal amplitudes of the welded conductive yarns were slightly higher than their reference values. Nevertheless, the noise amplitudes changed. For instance, those noise amplitudes of samples subjected to welding set 2 conditions $\left(\mathrm{T}=450^{\circ} ; \mathrm{v}=2.5 \mathrm{~m} / \mathrm{min}, \mathrm{p}=6.5\right.$ bar) ranged between $0.036 \mathrm{~V}$ and $0.08 \mathrm{~V}$. More particularly, it was observed that the noise amplitudes of the silver-coated yarns with PA were less than those of stainless steel yarns at this welding condition. However, the noise amplitudes of those samples welded under the weld sets 1 and 3 did not show any significant change. Figure 8 shows the SNRs of the welded transmission lines.

It was evident from this figure that in all cases after the welding processes the SNR values of the samples increased. It was also observable that after the welding processes the SNR values of the silver-coated polyamide yarns (yarn No.5, yarn No.6 and yarn No.7) were higher than those of the stainless steel yarns (yarn No.1, yarn No.2, yarn No.3 and yarn No.4). In other words, after the welding processes those transmission lines made of silver-coated polyamide conductive yarns showed better signal transference capabilities compared to those transmission lines made of stainless steel conductive yarns.

This can probably be explained by the shielded electrical cable principle. As it is a known fact that shielded cable conducts an electrical signal using an inner conductor wrapped within an insulated layer. Thus, the signal transmission inside the cable is protected by an outer shell from the electric and magnetic fields outside that cause interferences to signals inside the cable [27]. In our case, the coated conductive fibers positioned between PES fabric and the membranes were held together by adhesion. Therefore the outer surface of the conductive yarns was hidden in the structure and was wrapped by bonds of membrane and PES fabric together where it behaves like a shielded cable with a bonded outer shell. By this way, the conductive yarns hidden in the structure may be protected from the noise around and thus, their signal transferring capability may show an increase. Indeed, this property obtained as a result of a welding process makes the welded transmission lines a good choice for carrying weak signals.

Apart from these results, significant differences were also noticed among the applied welding processes. With reference to Figure 8, it was clearly seen that with weld set 3 $\left(\mathrm{T}=350{ }^{\circ} \mathrm{C} ; \mathrm{v}=1.5 \mathrm{~m} / \mathrm{min} ; \mathrm{p}=6.5 \mathrm{bar}\right)$, mostly higher $\mathrm{SNR}$ values were obtained. In other words, those samples welded at $\mathrm{T}=350{ }^{\circ} \mathrm{C}, \mathrm{v}=1.5 \mathrm{~m} / \mathrm{min}$ and $\mathrm{p}=6.5$ bar showed better signal transference capabilities compared to the other welded samples.

Figure 9 shows the comparisons between the SNR values of textile transmission lines due to the weld velocity when $\mathrm{T}=350{ }^{\circ} \mathrm{C}$ and $\mathrm{p}=6.5$ bar.

As seen from Figure 9 by increasing weld velocity from $1.5 \mathrm{~m} / \mathrm{min}$ to $2.5 \mathrm{~m} / \mathrm{min}$, the SNR values of the transmission lines decreased. As mentioned earlier, this may be explained by exposure time. As the exposure time increased adhesion between surfaces increased and thus the surface of the conductive yarn became better welded and bonded. This phenomenon indeed provides a basis for the formation of a bonded outer shell for conductive yarn and by this outer layer those electric and magnetic fields outside causing

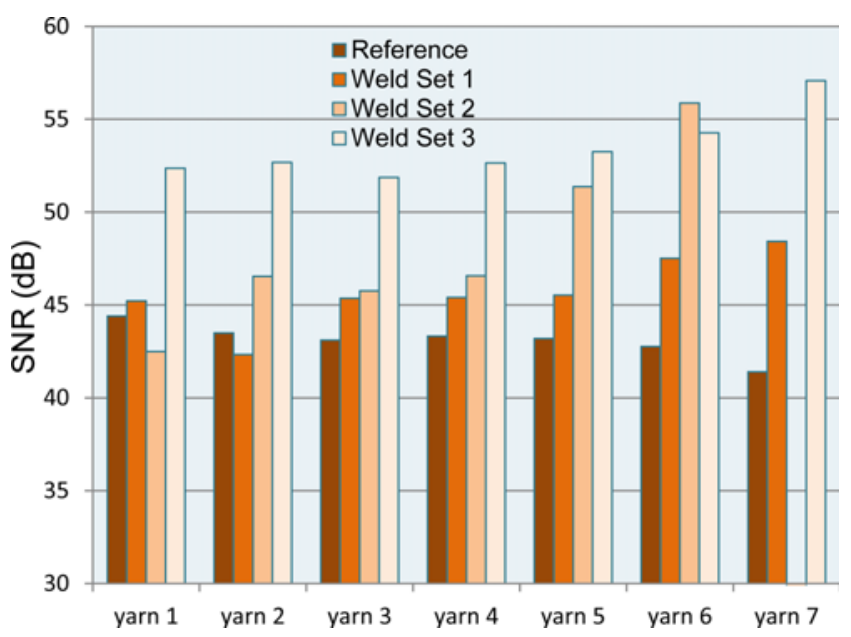

Figure 8. Comparison of SNR values of welded samples (Weld Set 1: $\mathrm{T}=350{ }^{\circ} \mathrm{C}, \mathrm{v}=2.5 \mathrm{~m} / \mathrm{min}, \mathrm{p}=6.5$ bar; Weld Set $2: \mathrm{T}=450{ }^{\circ} \mathrm{C}$, $\mathrm{v}=2.5 \mathrm{~m} / \mathrm{min}, \mathrm{p}=6.5$ bar; Weld Set $3: \mathrm{T}=350^{\circ} \mathrm{C}, \mathrm{v}=1.5 \mathrm{~m} / \mathrm{min}$, $\mathrm{p}=6.5 \mathrm{bar})$.

Table 4. Signal analysis results

\begin{tabular}{|c|c|c|c|c|c|c|c|c|c|c|c|c|c|c|}
\hline & \multicolumn{2}{|c|}{ Yarn 1} & \multicolumn{2}{|c|}{ Yarn 2} & \multicolumn{2}{|c|}{ Yarn 3} & \multicolumn{2}{|c|}{ Yarn 4} & \multicolumn{2}{|c|}{ Yarn 5} & \multicolumn{2}{|c|}{ Yarn 6} & \multicolumn{2}{|c|}{ Yarn 7} \\
\hline & Amplit & $\operatorname{de}(\mathrm{V})$ & Amplit & ude (V) & Amplitu & ade (V) & Amplit & ude (V) & Amplit & ude (V) & Amplitu & $\operatorname{de}(\mathrm{V})$ & Ampli & tude (V) \\
\hline & Signal $_{\text {RMS }}$ & Noise $_{\text {RN }}$ & Signal $_{\text {RMS }}$ & Noise $_{\text {RM }}$ & Signal $_{\text {RMS }}$ & Noise $_{\text {RMs }}$ & Signal $_{\text {RMS }}$ & Noise $_{\text {RMS }}$ & Signal $_{\text {RMS }}$ & Noise $_{\text {RMS }}$ & Signal $_{\text {RMS }}$ & Noise $_{\text {RMS }}$ & Signal $_{\mathrm{RM}}$ & Noise $_{\text {RMS }}$ \\
\hline Reference & 4.783 & 0.029 & 4.785 & 0.032 & 4.783 & 0.033 & 4.783 & 0.033 & 4.775 & 0.033 & 4.762 & 0.035 & 4.704 & 0.040 \\
\hline Weld Set 1 & 4.790 & 0.026 & 4.782 & 0.037 & 4.791 & 0.026 & 4.791 & 0.026 & 4.791 & 0.025 & 4.795 & 0.020 & 4.796 & 0.018 \\
\hline Weld Set 2 & 4.786 & 0.036 & 4.793 & 0.023 & 4.792 & 0.025 & 4.793 & 0.022 & 4.798 & 0.013 & 4.799 & 0.008 & $*$ & $*$ \\
\hline Weld Set 3 & 4.798 & 0.012 & 4.799 & 0.011 & 4.798 & 0.012 & 4.798 & 0.011 & 4.799 & 0.010 & 4.799 & 0.009 & 4.799 & 0.007 \\
\hline
\end{tabular}




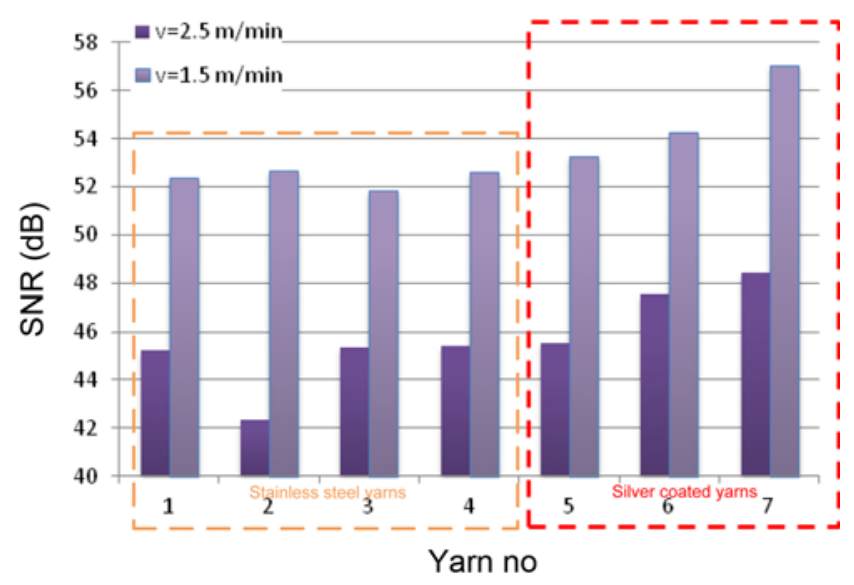

Figure 9. Comparison of SNRs of transmission lines due to welded velocity when $\mathrm{T}=350{ }^{\circ} \mathrm{C}$ and $\mathrm{p}=6.5$ bar.

interferences can be prevented so that the signal transmission quality inside the fabric layer can increase. This explains the reason for the decreases in the signal transference capabilities of the transmission lines when the welding speed was increased from $1.5 \mathrm{~m} / \mathrm{min}$ to $2.5 \mathrm{~m} / \mathrm{min}$. With reference to Figure 9 , it was also possible to notice that that the SNR values for stainless steel and silver-coated PA yarns were apparently different from each other. From the results, it was generally observed that the SNR values of the transmission lines created with silver coated PA were slightly higher than those of transmission lines created with stainless steel yarn. That means, transmission lines created with silver coated PA yarns showed better signal qualities than those created with stainless steel.

Overall, considering all the results from the conductivity tests and signal analysis, setting-up weld parameters at $\mathrm{T}=350{ }^{\circ} \mathrm{C}, \mathrm{v}=1.5 \mathrm{~m} / \mathrm{min}$ and $\mathrm{p}=6.5$ bar could be suggested as an optimal welding process in order to have better electrical properties for welded textile transmission lines.

\section{Visual Appearances}

The end quality regarding the visual appearances of welded seams depends on the structure, construction and fineness of the selected layers, fineness of the conductive yarns and the welding parameters. Table 5 shows a subjective evaluation of visual appearance regarding hot air welded textile transmission lines.

The puckering of textile transmission lines was very low in all the welded sets. Yarn No.3 had the higher puckering followed by yarns No. 2 and No.4, which were stainless steel conductive yarns. The main problem arising after the welding process is the occurrences of conductive yarns on the surfaces of the face-sides of those seams below the second layer Goratex ${ }^{\circledR}$. High frequencies regarding the conductive yarns used as transmission lines were observed for yarns No.2 and 5, while low frequencies of occurrence were observed for yarns No.1, 3 and 4 in all welded sets. Indeed, these effects appeared because of usage of very thin Goratex ${ }^{\circledR}$ membrane as the second layer when compared with the conductive yarn thickness. In the cases of yarns No.6 and No.7 the welded seams were smooth (no puckering and yarn visual points) since these yarns were composed of very thin fibers with low twist. Figure 10 shows the visual appearances of some of the samples welded under weld set 1 and weld set 3 . Three conductive yarns used as transmission lines were chosen for each weld set in order to show the visual appearance differences due to yarn thickness. It was clearly noticed that with yarn No.7 better surface appearance was obtained since it was the thinnest yarn among the sample yarns with a diameter of $142 \mu \mathrm{m}$. However, despite the increase in yarn thickness, the results were still promising. Nevertheless, during the manufacturing of transmission lines via the hot air seam-sealing machine, it was seen that different morphological events had taken place on the surfaces of the transmission lines depending on the materials' characteristics like being twisted or untwisted, small diameters, thin, etc. For instance, with yarn No.4 (low twist and moderate diameter), crimps as seen in Figure 10 were observed over the seam after manufacturing the transmission lines. This was probably due to direct bonding of the PET fabric and membrane through the gaps inside the conductive fibers. For instance; Figure 11 shows a longitudinal microscopic image

Table 5. Subjective evaluation of surface appearance of hot air welded conductive yarns

\begin{tabular}{|c|c|c|c|c|c|c|}
\hline \multirow{3}{*}{ Yarn code. } & \multicolumn{6}{|c|}{ Visual appearance } \\
\hline & \multicolumn{2}{|r|}{ Welded set 1} & \multicolumn{2}{|r|}{ Welded set 2} & \multicolumn{2}{|r|}{ Welded set 3} \\
\hline & Grade & $\begin{array}{c}\text { Frequency of occurrence of } \\
\text { yarn visual points }\end{array}$ & Grade & $\begin{array}{c}\text { Frequency of occurrence of } \\
\text { yarn visual points }\end{array}$ & Grade & $\begin{array}{c}\text { Frequency of occurrence of } \\
\text { yarn visual points }\end{array}$ \\
\hline 1 & 5 & Slightly & 5 & Slightly & 5 & Slightly \\
\hline 2 & 4 & High & 4 & High & 4 & High \\
\hline 3 & $3-4$ & Slightly & $3-4$ & Slightly & $3-4$ & Slightly \\
\hline 4 & 4 & Slightly & 4 & Slightly & 4 & Slightly \\
\hline 5 & 5 & High & 5 & High & 5 & High \\
\hline 6 & 5 & No & 5 & No & 5 & No \\
\hline 7 & 5 & No & & No seam was formed & 5 & No \\
\hline
\end{tabular}



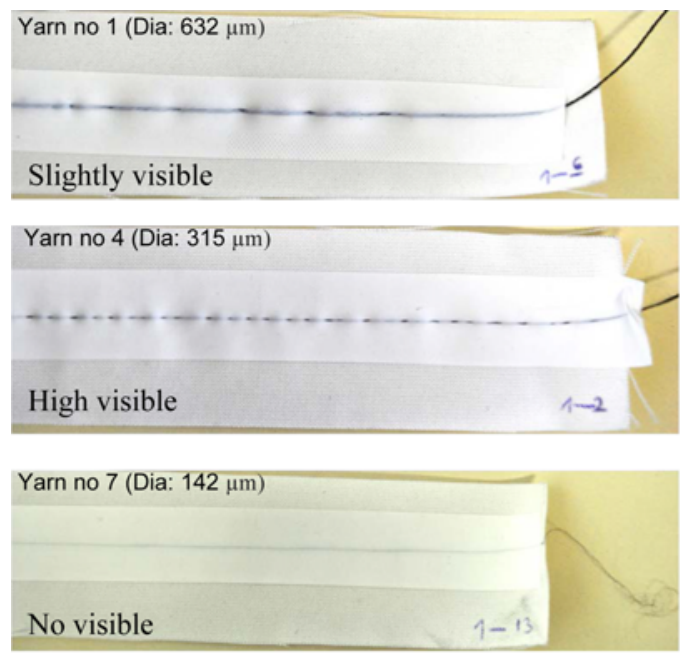

(a)
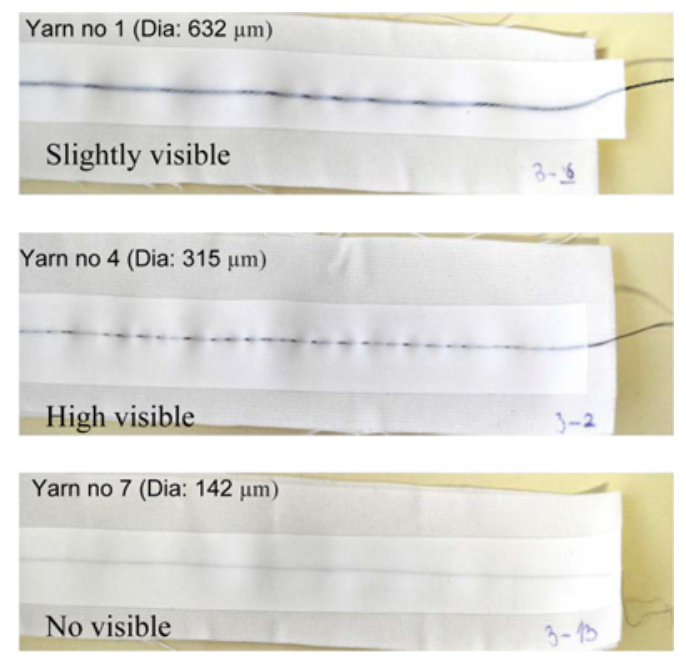

(b)

Figure 10. Visual appearances of some of the welded samples; (a) weld set 1 and (b) weld set 3 .

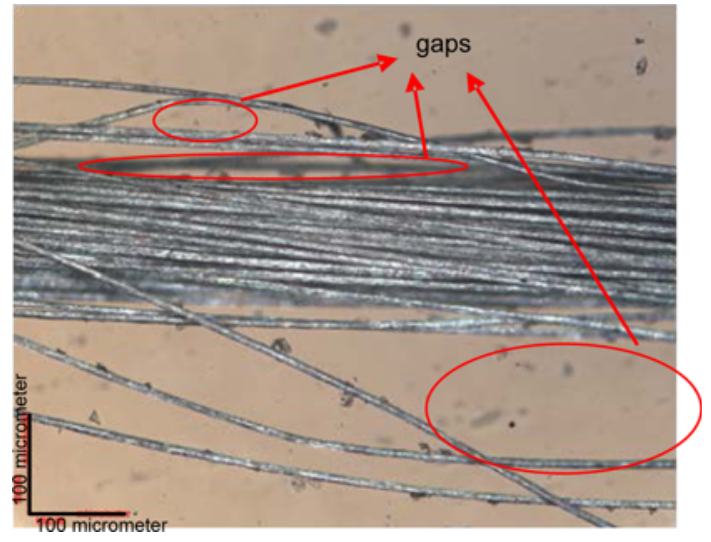

Figure 11. Microscopic image of yarns (a) No.4 (count: $90 \times 1$, diameter: $315 \mu \mathrm{m})$.

of yarn No.4. As apparently seen in Figure 11, the low twisted conductive yarn No.4 had filaments positioned horizontally with included gaps between each other. Through these gaps direct bonding between the PET fabric and membrane probably occurred, and this then caused the etextile structure to have a crimpy surface, Figure 11. Additionally, during the manufacturing of transmission lines in the case where the 2 nd layer was very thin, it was realized that working with silver-plated yarns was fairly easy compared to stainless steel yarns, for obtaining flattened transmission lines. Since the stainless steel yarns were stiffer with higher twisting ratios and higher in weights than silver-plated ones, they caused a negative effect on the welded seam appearance.

Figure 12 shows the micrographs of the welded conductive yarn inside the two-layered fabric structure. The crosssections of the welded seam show the position and shape of conductive yarn no. 1 after welding.

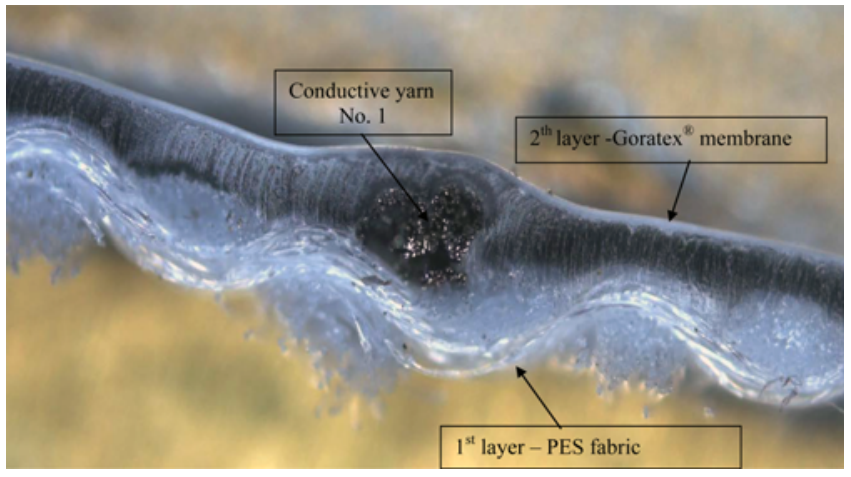

Figure 12. Cross section of hot welded seam with conductive yarn.

The conductive yarn no 1 was twisted with three yarns $(275 \times 3)$ and after hot air welding no change was observed of its cross-sectional shape. The thin Goratex ${ }^{\mathbb{B}}$ membrane was adapted to the conductive yarn shape and, therefore, the surface smoothness around the conductive yarns of the welded seams depended on thicknesses and constructions of the yarns and selected fabrics. The same conclusion was made regarding all the used conductive yarns. During additional research analyses of the visual appearances and cross-sections of hot air welded seams were needed due to the selection of suitable conductive yarns and fabrics for manufacturing the high quality products of e-transmission lines.

\section{Bending Results}

The bending rigidities of the welded textile transmission lines were evaluated on the faces and back-sides in the warp direction, Figure 13.

As was expected the bending rigidities increased after the 

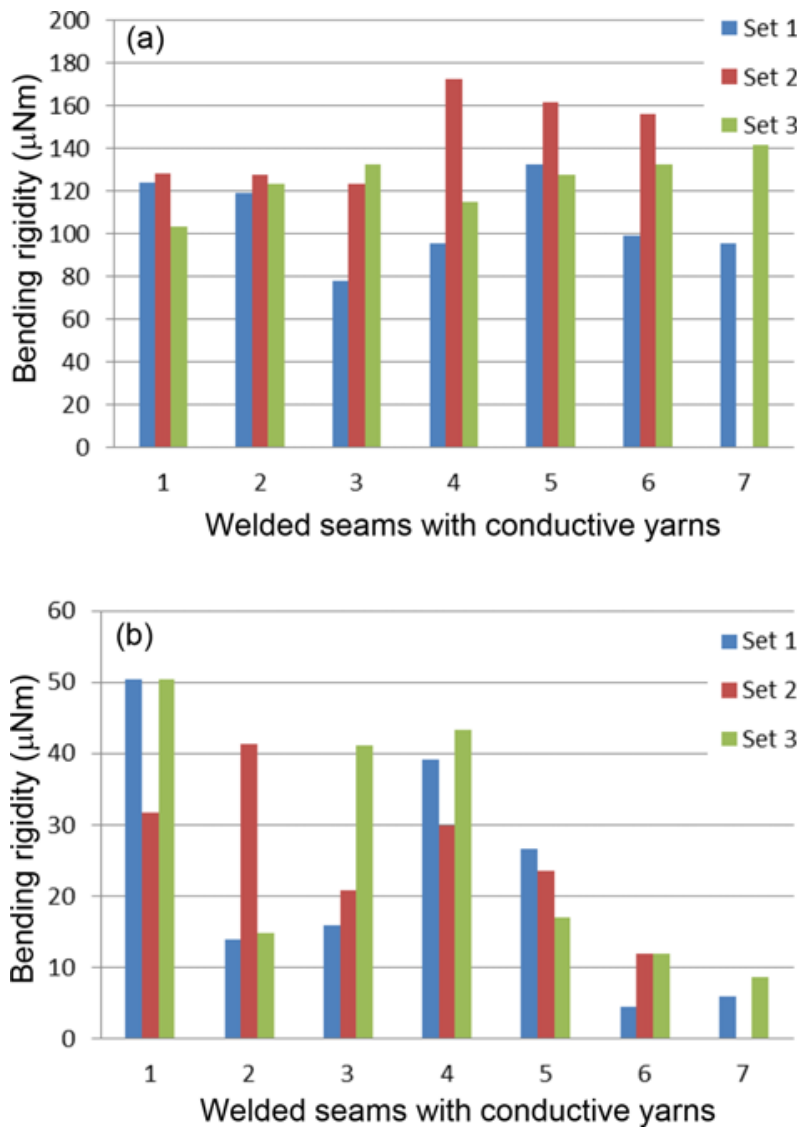

Figure 13. Bending rigidity of welded seams measured from (a) face side and (b) back side.

welding process. The highest increase in bending rigidity was noted when bending was measured on the face-sides of the welded transmission lines. Indeed this phenomenon is very important for the production issues of interactive clothing. From a manufacturing point of view, the fabric is converted from two to three dimensional shapes during the garment design process. Therefore, it should be noted that for designing interactive clothing, fabrics including textile transmission lines should be placed within the clothing system when considering this issue. The inner-sides of textile transmission lines must be more flexible than the outsides in order to obtain the desired tridimensional shape.

In addition, by increasing the welding temperature it was found that the bending rigidities of welded textile transmission lines generally increase from the face-side. The textile transmission lines formed at weld set $2\left(\mathrm{~T}=450{ }^{\circ} \mathrm{C}\right.$, velocity $2.5 \mathrm{~m} / \mathrm{min}, \mathrm{p}=6.5 \mathrm{bar}$ ) conditions were stiffer than other transmission lines welded at lower welding temperatures (Weld sets 1 and 3). On the other hand, the higher welding temperature meant more energy-consumption. Thus, this result is also satisfying from the aspects of production cost issues. Therefore, from the obtained results welding at low temperatures could also be suggested when considering production management and cost issues.

\section{Conclusion}

Hot air sealing investigations for obtaining textile transmission lines were conducted using different conductive yarn types for forming textile transmission lines at different weld temperatures and speeds. The obtained results based on conductivity and signal transference capabilities were promising for the manufacturing of e-textile transmission lines via hot air welding technology. The produced transmission lines had adequate electrical properties at certain combinations of parameters. However, using conductive yarns with a linear resistance of less than $200 \mathrm{ohm} / \mathrm{m}$ could be recommended in order to preserve conductivity levels on the transmission lines after the welding process. When considering all the electrical properties of signal transmission lines, the settingup of weld parameters at $\mathrm{T}=350^{\circ} \mathrm{C}, \mathrm{v}=1.5 \mathrm{~m} / \mathrm{min}$ and $\mathrm{p}=$ 6.5 bar could be suggested as an optimal welding process for the formations of textile transmission lines. Also, the bending rigidity tests on the welded transmission lines confirmed that the lower the welding parameters the more pliable the hot air welded textile transmission lines became after welding for all the used conductive yarns. It was also discovered that the visual appearances of the welded transmission lines mainly depend on the selected conductive yarn properties and textile materials for layers rather than the selected welding parameters.

In conclusion, from this study the use of hot air welding technology was proven to be a convenient technique for constructing reliable and durable transmission lines while preserving the textile aspects, thus representing a great challenge and significant contribution to the e-textile research arena. However, hot air sealing parameters need to be carefully controlled to avoid excessive melting and polymer degradation. As future work, different welding parameters for the different types of fabric structures can be studied to form e-textile transmission lines with different conductive yarn types.

\section{Acknowledgements}

This project has received funding from the European Union's Horizon 2020 research and innovation programme under the Marie Skłodowska-Curie grant agreement No 644268. In addition, this research work was supported by TUBITAK (The Scientific \& Technological Research Council of Turkey) Project no. 214M405 and BIDEB (Science Fellowships \& Grant Programs Department), 2221 - Fellowships for Visiting Scientists and Scientists on Sabbatical Leave, for the period 2014-2015.

\section{References}

1. G. Belforte, G. Eula, A. Ivanov, R. Grassi, and H. Askrim, 
J. Text. Inst., 105, 717 (2014).

2. S. Pappada, A. Salomi, and A. Montanaro, Compos. Mag., 51, 89 (2014).

3. S. H. Eryürük, F. Kalaoğlu, B. Karagüzel Kayaoglu, S. Jevšnik, T. Rijavec, P. Komarkova, and V. Golombikova, "Proc. of 14th Autex Conference 2014", pp.48-54, Bursa, 2014.

4. E. Violleau, Compos. Mag., 87, 92 (2014).

5. J. Prabir, Indian J. Text. Res., 36, 380 (2011).

6. P. Kah and J. Martikainen, Adv. Mater. Sci., 30, 189 (2012).

7. I. Jones in "Joining Textiles. Principle and Application", 1st ed. (G. Stylious Ed.), pp.355-373, Woodhead Publishing, Cambrige, 2013.

8. R. Shishoo, "The Global Textile and Clothing Industry", 1st ed. (R. Shishoo Ed.), Woodhead Publishing, Cambridge, 2012.

9. K. Swantko, "Fabric Trends", Summer 2004, 12-14 (2004) http://www.thetechnicalcenter.com/features/Assets/ WeldedGT0804.pdf. Accessed: 10 June 2015.

10. Ž. Jakubčionienè and V. Masteikaitè, Mater. Sci., 16, 1 (2010).

11. N. Seram and D. Cabon, Int. J. Cloth. Sci. Technol., 25, 90 (2013).

12. S. Ghosh and R. Reddy, J. Appl. Polym. Sci., 113, 1082 (2009).

13. W. Shi and T. Little, Int. J. Cloth. Sci. Technol., 12, 333 (2000).

14. M. Hustedt, J. Stein, D. Herzog, and O. Meier, "Proc. 3th World Automotive Congress Plastics-in-Motion 2008", pp.1-11, Wisconsin, 2008.

15. A. Wêglowska, Polimery, 59, 239 (2014).
16. S. A. Odhiambo, D. M. Gilbert, C. Hertleer, A. Schwarz, and L. V. Langenhove, Text. Res. J., 84, 347 (2014).

17. J. Leśnikowski, Fibres Text. East. Eur., 19, 89 (2011).

18. D. Negru, C. T. Buda, and D. Avram, Fibres Text. East. Eur., 1, 53 (2012).

19. B. Kim, V. Koncar, and C. Dufour, J. Appl. Polym. Sci., 101, 1252 (2006).

20. E. Gasana, P. Westbroek, J. Hakuzimana, K. De Clerck, G. Priniotakis, P. Kikens, and D. Tseles, Surf. Coat. Technol., 201, 3547 (2006).

21. S. Vassiliadis, "Electronics and Computing in Textiles", Bookboon.com, 2012.

22. S. Kursun-Bahadir, V. Koncar, F. Kalaoglu, I. Cristian, and S. Thomassey, Fibres Text. East. Eur., 19, 75 (2011).

23. C. Renumadhavi, S. Madhava Kumar, A. G. Ananth, and N. Srinivasan, "Proc. of 6th WSEAS International Conference on Simulation, Modelling and Optimization", pp.202-205, Wisconsin, 2006.

24. A De Boss, "The FAST System for Objective Measurement of Fabric Properties, Operation, Interpretation and Application", 1st ed. CSIRO Division of Wool Technology Operation, Interpretation and Application, CSIRO Division of Wool Technology, Sydney, 1998.

25. R. Alagirusamy, J. Eichhoff, T. Gries, and S. Jockenhoevel, J. Text. Inst., 104, 270 (2013).

26. W. Rehnby, M. Gustafsson, and M. Skrifvars, "Proc. of Ambience 2008”, pp.100-103, Borås, 2008.

27. H. Ward Silver and M. J. Wilson, "Transmission Lines", 87th ed., The ARRL Handbook for Radio Communications, The American Radio Relay League, 2010. 